\title{
STATCOM based Power Quality Improvement in a Hybrid System
}

\author{
Akash A. Ukunde ${ }^{1}$, Radharaman Shaha ${ }^{2}$ \\ ${ }^{1}$ PG Scholar, Department of Electrical Engineering, A.G. Patil College of Engineering, Nagpur, Maharashtra, India \\ ${ }^{2}$ Head, Department of Electrical Engineering, A.G. Patil College of Engineering, Nagpur, Maharashtra, India
}

\begin{abstract}
With the conventional energy depleting very fast and the power demand increasing every passing day, it has become absolute necessary to focus on renewable energy. Lots and lots of project are being undertaken which are able to harness power from the renewable energy sources like, sun, wind, water, etc. The integration of these systems (wind energy, hydro energy, solar power etc.) created different kinds of problems in the grid like system stability problems or power quality issues which needs to be resolved. Conventionally passive filters were used but nowadays active filters such as Static Synchronous Compensator (STATCOM) and Dynamic Voltage Restorer (DVR) are chosen for the task. STATCOM is a device that regulates the voltage level or the reactive power in the system. It is used to maintain voltage stability, enlargement of critical clearing time. This work intends to propose the use of STATCOM for maintaining the power quality. The simulation has been carried in MATLAB/SIMULINK and results are presented to validate the claim.
\end{abstract}

Keywords: STATCOM, PMSG wind turbine, Harmonics

\section{Introduction}

Power Quality (PQ) related issues are of most concern nowadays. The widespread use of electronic equipment, such as information technology equipment, power electronics such as adjustable speed drives (ASD), programmable logic controllers (PLC), energy-efficient lighting, led to a complete change of electric loads nature. These loads are simultaneously the major causers and the major victims of power quality problems. Due to their non-linearity, all these loads cause disturbances in the voltage waveform. Along with technology advance, the organization of the worldwide economy has evolved towards globalization and the profit margins of many activities tend to decrease. The increased sensitivity of the vast majority of processes (industrial, services and even residential) to PQ problems turns the availability of electric power with quality a crucial factor for competitiveness in every activity sector. The most critical areas are the continuous process industry and the information technology services.

When a disturbance occurs, huge financial losses may happen, with the consequent loss of productivity and competitiveness. Although many efforts have been taken by utilities, some consumers require a level of PQ higher than the level provided by modern electric networks. This implies that some measures must be taken in order to achieve higher levels of Power Quality.

Use of renewable energy has increased through time and integration of renewable energy such as wind, photovoltaic, fuel cell, and tidal to the grid solved many problems and replenished the exceeding and ascending need for electrical energy. Integration of the renewable energy with the grid has lead to a more complex electrical network or "Grid".

This enlargement and enrichment in equipment has caused problems such as stability, reliability and power quality [5], [6], [7] and [8]. The issue of power quality is of great importance to the to the wind turbine [6]. and there's a need to find solutions to these problems, using different technologies such as smart meters, monitoring system, controllers, remote ability.

The integration of wind energy into a weak system is a challenge; voltage fluctuation, voltage dips, swells and swags are created due to the uncontrollable resource and the nature of the DWIG (Distributed Wind Induction Generators) on the already weak system. This causes stability issues, reliability and power quality issues which need to be solved [9].

The rest of this paper is organized as follows. Section II reviews the techniques of harvesting power from renewable energy sources, Section III discusses the power quality issues, Section IV talks about improvement techniques followed by result analysis in Section $\mathrm{V}$ and conclusion in Section VI.

\section{Technique of Harvesting Power from Renewable Energy Sources}

Wind power is the use of air flow through wind turbines to mechanically power generators for electricity. Wind power, as an alternative to burning fossil fuels, is plentiful, renewable, widely distributed, clean, produces no greenhouse gas emissions during operation, and uses little land. The net effects on the environment are far less problematic than those of nonrenewable power sources.

Wind power gives variable power which is very consistent from year to year but which has significant variation over shorter time scales. It is therefore used in conjunction with other electric power sources to give a reliable supply. As the proportion of wind power in a region increases, a need to upgrade the grid, and a lowered ability to supplant conventional production can occur. Power management techniques such as having excess capacity, geographically 


\section{International Journal of Science and Research (IJSR) \\ ISSN (Online): 2319-7064}

Index Copernicus Value (2013): 6.14 | Impact Factor (2015): 6.391

distributed turbines, dispatchable backing sources, sufficient hydroelectric power, exporting and importing power to neighboring areas, using vehicle-to-grid strategies or reducing demand when wind production is low, can in many cases overcome these problems. In addition, weather forecasting permits the electricity network to be readied for the predictable variations in production that occur.

Today wind powered generators operate in every size range between tiny stations for battery charging at isolated residences, up to near-gigawatt sized offshore wind farms that provide electricity to national electrical networks.

Induction generators, which were often used for wind power projects in the 1980s and 1990s, required reactive power for excitation so substations used in wind-power collection systems include substantial capacitor banks for power factor correction. Today these generators aren't used any more in modern turbines. Instead today most turbines use variable speed generators combined with partialor full-scale power converter between the turbine generator and the collector system, which generally have more desirable properties for grid interconnection and have Low voltage ride through-capabilities. Modern concepts use either doubly fed machines with partial-scale converters or squirrel-cage induction generators or synchronous generators (both permanently and electrically excited) with full scale converters.

Transmission systems operators will supply a wind farm developer with a grid code to specify the requirements for interconnection to the transmission grid. This will include power factor, constancy of frequency and dynamic behaviour of the wind farm turbines during a system fault.

Since wind speed is not constant, a wind farm's annual energy production is never as much as the sum of the generator nameplate ratings multiplied by the total hours in a year. The ratio of actual productivity in a year to this theoretical maximum is called the capacity factor.

Electricity generated from wind power can be highly variable at several different timescales: hourly, daily, or seasonally. Annual variation also exists, but is not as significant. Because instantaneous electrical generation and consumption must remain in balance to maintain grid stability, this variability can present substantial challenges to incorporating large amounts of wind power into a grid system. Intermittency and the non-dispatchable nature of wind energy production can raise costs for regulation, incremental operating reserve, and (at high penetration levels) could require an increase in the already existing energy demand management, load shedding, storage solutions or system interconnection with HVDC cables.

Typically, conventional hydroelectricity complements wind power very well. When the wind is blowing strongly, nearby hydroelectric stations can temporarily hold back their water. When the wind drops they can, provided they have the generation capacity, rapidly increase production to compensate. This gives a very even overall power supply and virtually no loss of energy and uses no more water.
Alternatively, where a suitable head of water is not available, pumped-storage hydroelectricity or other forms of grid energy storage such as compressed air energy storage and thermal energy storage can store energy developed by high-wind periods and release it when needed.

Solar energy is radiant light and heat from the Sun harnessed using a range of ever-evolving technologies such as solar heating ,photovoltaics, solar thermal energy, solar architecture and artificial photosynthesis.

It is an important source of renewable energy and its technologies are broadly characterized as either passive solar or active solar depending on the way they capture and distribute solar energy or convert it into solar power. Active solar techniques include the use of photovoltaic systems, concentrated solar power and solar water heating to harness the energy. Passive solar techniques include orienting a building to the Sun, selecting materials with favorable thermal mass or light dispersing properties, and designing spaces that naturally circulate air.

The amount of solar energy reaching the surface of the planet is so vast that in one year it is about twice as much as will ever be obtained from all of the Earth's non-renewable resources of coal, oil, natural gas, and mined uranium combined, The potential solar energy that could be used by humans differs from the amount of solar energy present near the surface of the planet because factors such as geography, time variation, cloud cover, and the land available to humans limits the amount of solar energy that we can acquire.

Geography affects solar energy potential because areas that are closer to the equator have a greater amount of solar radiation. However, the use of photovoltaics that can follow the position of the sun can significantly increase the solar energy potential in areas that are farther from the equator. Time variation effects the potential of solar energy because during the nighttime there is little solar radiation on the surface of the Earth for solar panels to absorb. This limits the amount of energy that solar panels can absorb in one day. Cloud cover can affect the potential of solar panels because clouds block incoming light from the sun and reduce the light available for solar cells.

In addition, land availability has a large effect on the available solar energy because solar panels can only be set up on land that is unowned and suitable for solar panels. Roofs have been found to be a suitable place for solar cells, as many people have discovered that they can collect energy directly from their homes this way. Other areas that are suitable for solar cells are lands that are unowned by businesses where solar plants can be established.

Solar technologies are broadly characterized as either passive or active depending on the way they capture, convert and distribute sunlight and enable solar energy to be harnessed at different levels around the world, mostly depending on distance from the equator. Although solar energy refers primarily to the use of solar radiation for practical ends, all renewable energies, other than geothermal and tidal, derive their energy from the Sun in a direct or indirect way.

Active solar techniques use photovoltaics, concentrated solar power, solar thermal collectors, pumps, and fans to convert 


\section{International Journal of Science and Research (IJSR) \\ ISSN (Online): 2319-7064}

Index Copernicus Value (2013): 6.14 | Impact Factor (2015): 6.391

sunlight into useful outputs. Passive solar techniques include selecting materials with favorable thermal properties, designing spaces that naturally circulate air, and referencing the position of a building to the Sun. Active solar technologies increase the supply of energy and are considered supply side technologies, while passive solar technologies reduce the need for alternate resources and are generally considered demand side technologies.

In the last two decades, photovoltaics (PV), also known as solar PV, has evolved from a pure niche market of small scale applications towards becoming a mainstream electricity source. A solar cell is a device that converts light directly into electricity using the photoelectric effect. The first solar cell was constructed by Charles Fritts in the 1880s

Off-grid PV systems have traditionally used rechargeable batteries to store excess electricity. With grid-tied systems, excess electricity can be sent to the transmission grid, while standard grid electricity can be used to meet shortfalls. Pumped-storage hydroelectricity stores energy in the form of water pumped when energy is available from a lower elevation reservoir to a higher elevation one. The energy is recovered when demand is high by releasing the water, with the pump becoming a hydroelectric power generator.

\section{Power Quality Issues}

Various power quality issues that normally occur in a power system are listed below

\section{a) Voltage Sag}

Description: A decrease of the normal voltage level between 10 and $90 \%$ of the nominal rms voltage at the power frequency, for durations of 0,5 cycle to 1 minute.

Causes: Faults on the transmission or distribution network (most of the times on parallel feeders). Faults in consumer's installation. Connection of heavy loads and start-up of large motors.

Consequences: Malfunction of information technology equipment, namely microprocessor-based control systems (PCs, PLCs, ASDs, etc) that may lead to a process stoppage. Tripping of contactors and electromechanical relays. Disconnection and loss of efficiency in electric rotating machines.)

\section{b) Very Short Interruptions}

Description: Total interruption of electrical supply for duration from few milliseconds to one or two seconds.

Causes: Mainly due to the opening and automatic reclosure of protection devices to decommission a faulty section of the network. The main fault causes are insulation failure, lightning and insulator flashover.

Consequences: Tripping of protection devices, loss of information and malfunction of data processing equipment. Stoppage of sensitive equipment, such as ASDs, PCs, PLCs, if they're not prepared to deal with this situation.

\section{c) Long Interruptions}

Description: Total interruption of electrical supply for duration greater than 1 to 2 seconds
Causes: Equipment failure in the power system network, storms and objects (trees, cars, etc) striking lines or poles, fire, human error, bad coordination or failure of protection devices.

Consequences: Stoppage of all equipment.

\section{d) Voltage Spike}

Description: Very fast variation of the voltage value for durations from a several microseconds to few milliseconds. These variations may reach thousands of volts, even in low voltage.

Causes: Lightning, switching of lines or power factor correction capacitors, disconnection of heavy loads.

Consequences: Destruction of components (particularly electronic components) and of insulation materials, data processing errors or data loss, electromagnetic interference.

\section{e) Voltage Swell}

Description: Momentary increase of the voltage, at the power frequency, outside the normal tolerances, with duration of more than one cycle and typically less than a few seconds.

Causes: Start/stop of heavy loads, badly dimensioned power sources, badly regulated transformers (mainly during offpeak hours)

Consequences: Data loss, flickering of lighting and screens, stoppage or damage of sensitive equipment, if the voltage values are too high.

\section{f) Harmonic Distortion}

Description: Voltage or current waveforms assume nonsinusoidal shape. The waveform corresponds to the sum of different sine-waves with different magnitude and phase, having frequencies that are multiples of power-system frequency.

Causes: Classic sources: electric machines working above the knee of the magnetization curve (magnetic saturation), arc furnaces, welding machines, rectifiers, and DC brush motors. Modern sources: all non-linear loads, such as power electronics equipment including ASDs, switched mode power supplies, data processing equipment, high efficiency lighting. Consequences: Increased probability in occurrence of resonance, neutral overload in 3-phase systems, overheating of all cables and equipment, loss of efficiency in electric machines, electromagnetic interference with communication systems, errors in measures when using average reading meters, nuisance tripping of thermal protections.

\section{g) Voltage Fluctuation}

Description: Oscillation of voltage value, amplitude modulated by a signal with frequency of 0 to $30 \mathrm{~Hz}$.

Causes: Arc furnaces, frequent start/stop of electric motors (for instance elevators), oscillating loads.

Consequences: Most consequences are common to undervoltages. The most perceptible consequence is the flickering of lighting and screens, giving the impression of unsteadiness of visual perception.

\section{h) Noise}

Description: Superimposing of high frequency signals on the waveform of the power-system frequency. 


\section{International Journal of Science and Research (IJSR) \\ ISSN (Online): 2319-7064}

Index Copernicus Value (2013): 6.14 | Impact Factor (2015): 6.391

Causes: Electromagnetic interferences provoked by Hertzian waves such as microwaves, television diffusion, and radiation due to welding machines, arc furnaces, and electronic equipment. Improper grounding may also be a cause.

Consequences: Disturbances on sensitive electronic equipment, usually not destructive. May cause data loss and data processing errors.

\section{i) Voltage Unbalance}

Description: A voltage variation in a three-phase system in which the three voltage magnitudes or the phaseangle differences between them are not equal.

Causes: Large single-phase loads (induction furnaces, traction loads), incorrect distribution of all single-phase loads by the three phases of the system (this may be also due to a fault).

Consequences: Unbalanced systems imply the existence of a negative sequence that is harmful to all three phase loads. The most affected loads are three-phase induction machines

\section{Power Quality Improvement Techniques}

The mitigation of PQ problems may take place at different levels: transmission, distribution and the end use equipment. Several measures can be taken at these levels.

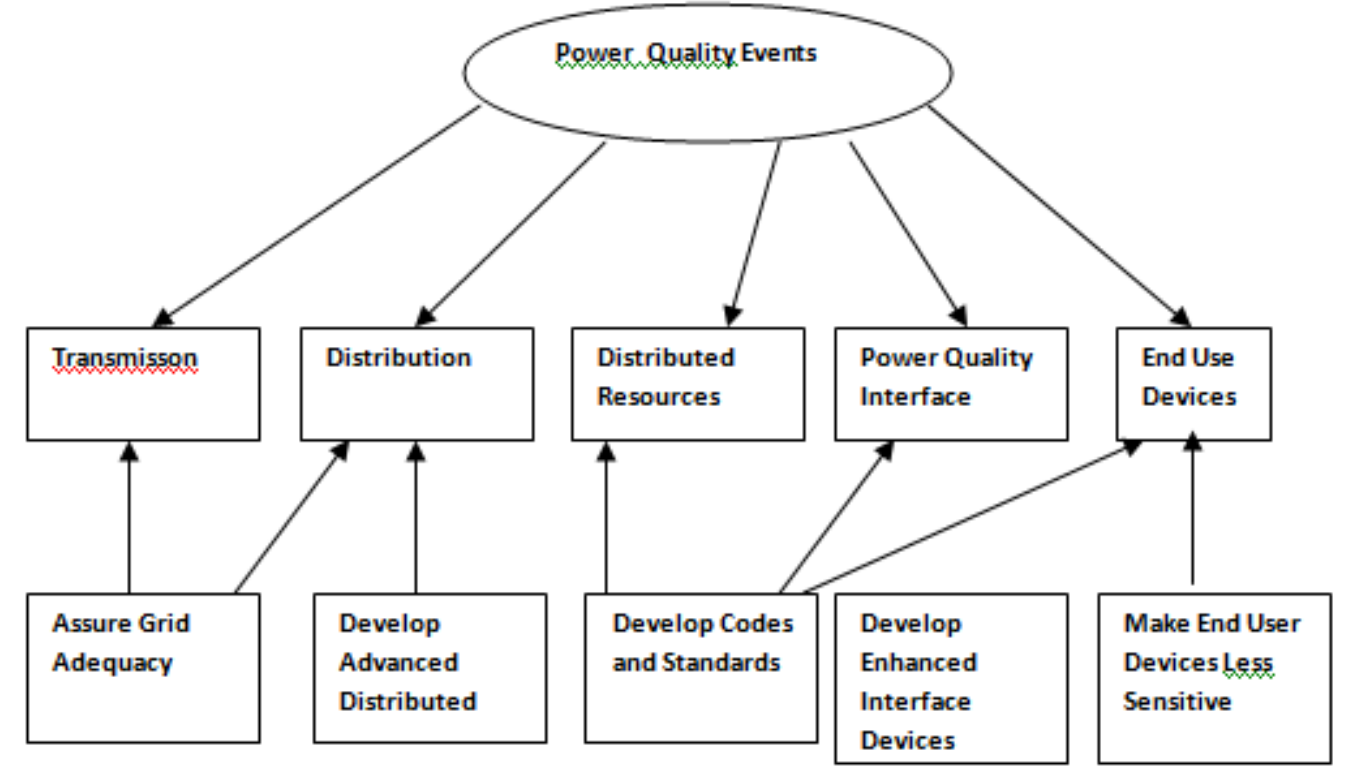

Figure 2: Power quality issues and solutions

\section{Grid Adequacy}

Many PQ problems have origin in the transmission or distribution grid. Thus, a proper transmission and distribution grid, with adequate planning and maintenance, is essential to minimize the occurrence of PQ problems.

\section{Distributed Resources - Energy Storage Systems}

Interest in the use of distributed energy resources (DER) has increased substantially over the last few years because of their potential to provide increased reliability. These resources include distributed generation and energy storage systems. Energy storage systems, also known as restoring technologies, are used to provide the electric loads with ridethrough capability in poor PQ environment.

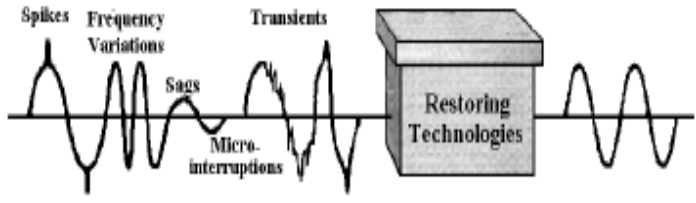

Figure 1: Principle of power restoration

Recent technological advances in power electronics and storage technologies are turning the restoring technologies one of the premium solutions to mitigate PQ problems
The first energy storage technology used in the field of PQ, yet the most used today, is electrochemical battery. Although new technologies, such as flywheels, super capacitors and superconducting magnetic energy storage (SMES) present many advantages, electrochemical batteries still rule due to their low price and mature technology.

\section{A. Flywheels}

A flywheel is an electromechanical device that couples a rotating electric machine (motor/generator) with a rotating mass to store energy for short durations. The motor/generator draws power provided by the grid to keep the rotor of the flywheel spinning. During a power disturbance, the kinetic energy stored in the rotor is transformed to DC electric energy by the generator, and the energy is delivered at a constant frequency and voltage through an inverter and a control system. The flywheel provides power during a period between the loss of utility supplied power and either the return of utility power or the start of a back-up power system (i.e., diesel generator). Flywheels typically provide 1-100 seconds of ride-through time, and back-up generators are able to get online within 5-20 seconds.

\section{B. Supercapacitors}

Supercapacitors (also known as ultracapacitors) are DC energy sources and must be interfaced to the electric grid with a static power conditioner, providing energy output at the grid frequency. A supercapacitor provides power during

\section{Volume 5 Issue 6, June 2016} www.ijsr.net 


\section{International Journal of Science and Research (IJSR) \\ ISSN (Online): 2319-7064}

Index Copernicus Value (2013): 6.14 | Impact Factor (2015): 6.391

short duration interruptions or voltage sags. Medium size supercapacitors (1 MJoule) are commercially available to implement ride-through capability in small electronic equipment, but large supercapacitors are still in development, but may soon become a viable component of the energy storage field.

\section{SMES}

A magnetic field is created by circulating a DC current in a closed coil of superconducting wire. The path of the coil circulating current can be opened with a solid-state switch, which is modulated on and off. Due to the high inductance of the coil, when the switch is off (open), the magnetic coil behaves as a current source and will force current into the power converter which will charge to some voltage level. Proper modulation of the solid-state switch can hold the voltage within the proper operating range of the inverter, which converts the DC voltage into AC power.

\section{Distributed Resources - Distributed Generation}

Distributed Generation (DG) units can be used to provide clean power to critical loads, isolating them from disturbances with origin in the grid. DG units can also be used as backup generators to assure energy supply to critical loads during sustained outages. Additionally DG units can be used for load management purposed to decrease the peak demand. At present, reciprocating engine is the prevalent technology in DG market, but with technology advancements, other technologies are becoming more attractive, such as microturbines or fuel cells

\section{Enhanced Interface Devices}

Besides energy storage systems and DG, some other devices may be used to solve PQ problems. Using proper interface devices, one can isolate the loads from disturbances deriving from the grid.

\section{A. Dynamic Voltage Restorer}

A dynamic voltage restorer (DVR) acts like a voltage source connected in series with the load. The output voltage of the DVR is kept approximately constant voltage at the load terminals by using a step-up transformer and/or stored energy to inject active and reactive power in the output supply trough a voltage converter.

\section{B. Transient Voltage Surge suppressors (TVSS)}

Transient voltage surge suppressors are used as interface between the power source and sensitive loads, so that the transient voltage is clamped by the TVSS before it reaches the load. TVSSs usually contain a component with a nonlinear resistance (a metal oxide varistor or a zener diode) that limits excessive line voltage and conduct any excess impulse energy to ground.

\section{Constant Voltage Transformers}

Constant voltage transformers (CVT) were one of the first PQ solutions used to mitigate the effects of voltage sags and transients. To maintain the voltage constant, they use two principles that are normally avoided: resonance and core saturation. When the resonance occurs, the current will increase to a point that causes the saturation of the magnetic core of the transformer. If the magnetic core is saturated, then the magnetic flux will remain roughly constant and the transformer will produce an approximately constant voltage output. If not properly used, a CVT will originate more PQ problems than the ones mitigated. It can produce transients, harmonics (voltage wave clipped on the top and sides) and it is inefficient (about $80 \%$ at full load). Its application is becoming uncommon due to technological advances in other areas.

\section{Noise Filters}

Noise filters are used to avoid unwanted frequency current or voltage signals (noise) from reaching sensitive equipment. This can be accomplished by using a combination of capacitors and inductances that creates a low impedance path to the fundamental frequency and high impedance to higher frequencies, that is, a low-pass filter. They should be used when noise with frequency in the $\mathrm{kHz}$ range is considerable.

\section{E. Isolation Transformers}

Isolation transformers are used to isolate sensitive loads from transients and noise deriving from the mains. In some cases (Delta-Wye connection) isolation transformers keep harmonic currents generated by loads from getting upstream the transformer. The particularity of isolation transformers is a grounded shield made of nonmagnetic foil located between the primary and the secondary. Any noise or transient that come from the source in transmitted through the capacitance between the primary and the shield and on to the ground and does not reach the load.

\section{F. Static VAR Compensators}

Static VAR compensators (SVR) use a combination of capacitors and reactors to regulate the voltage quickly. Solidstate switches control the insertion of the capacitors and reactors at the right magnitude to prevent the voltage from fluctuating. The main application of SVR is the voltage regulation in high voltage and the elimination of flicker caused by large loads (such as induction furnaces).

\section{G. Harmonic Filters}

Harmonic filters are used to reduce undesirable harmonics. They can be divided in two groups: passive filters and active filters. Passive filters consist in a low impedance path to the frequencies of the harmonics to be attenuated using passive components (inductors, capacitors and resistors). Several passive filters connected in parallel may be necessary to eliminate several harmonic components. If the system varies (change of harmonic components), passive filters may become ineffective and cause resonance. Active filters analyse the current consumed by the load and create a current that cancel the harmonic current generated by the loads. Active filters were expensive in the past, but they are now becoming cost effective compensating for unknown or changing harmonics

\section{Develop Codes and Standards}

Some measures have been taken to regulate the minimum PQ level that utilities have to provide to consumers and the immunity level that equipment should have to operate properly when the power supplied is within the standards. One major step in this direction was taken with the CBEMA curve, created by the Computer and Business Equipment Manufacturer's Association. This standard specifies the 


\section{International Journal of Science and Research (IJSR) \\ ISSN (Online): 2319-7064 \\ Index Copernicus Value (2013): 6.14 | Impact Factor (2015): 6.391}

minimum withstanding capability of computer equipment to voltage sags, micro interruptions and over voltages.

\section{Make End-use Devices Less Sensitive}

Designing the equipment to be less sensitive to disturbances is usually the most cost effective measure to prevent PQ problems. Some manufacturers of end-use equipment are now recognising this problem, but the competitive market means that manufacturers should reduce costs and only respond to customers requirements. The exception is the ASD market, where manufacturers are actively promoting products with enhanced ride-through capabilities. Adding a capacitor with a larger capacity to power supplies, using cables with larger neutral conductors, derating transformers and adjusting undervoltage relays, are measures that could be taken by manufacturers to reduce the sensitivity of equipment to $\mathrm{PQ}$ problems.

\section{Proposed Hybrid Model}

Present day power system consider power quality as a critical issue. With use of sensitive and nonlinear loads in electrical power systems complimented by the rapid growth of renewable energy sources, together serve as a major reason of poor power quality. The basic issues are voltage dip, voltage swell, harmonic contents and so on. Major power quality problems can be solved by using custom power devices. STATCOM are recognized as a successful sort of custom power unit for maintaining the power quality at a low cost and higher energy capacity.

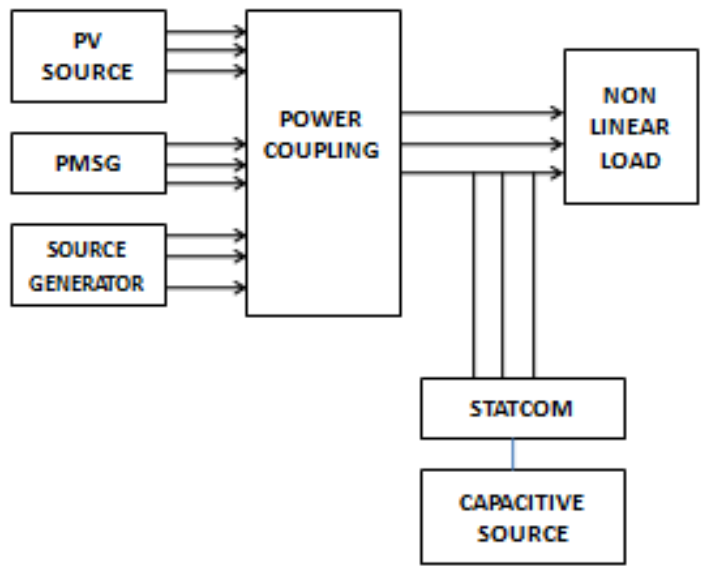

Figure 3: Proposed Hybrid Model

The Above block shows the proposed scheme in which the DVR and STATCOM. The figure above shows the grid or the infinite bus connected to the grid, it shows the WTIG, a non-linear load for harmonics generation. The DVR and STATCOM are used for Active filtering. They cancel the effect of voltage sags and swells by injecting a voltage into the system, and remove the harmonics by injecting a current into the system.

\section{STATCOM operation}

After the wind turbine is initialized and will be running and when the Non-Linear load will be connected to the system, the voltage and current at the Grid will be distorted and will need to be filtered. Here the STATCOM (Active filter) will be activated and will inject the exact current into the system needed to cancel the effect of the harmonics. This reference injected current will be generated by the hysteresis control technique.

The STATCOM has been identified a device which can quickly respond to assist in improving the power quality and stability of the wind farms. Previous studies have been limited to reactive power control only. STATCOM supplemented with a Battery storage system can provide more benefits to the wind farm and the associated power systems. Battery energy storage scores over other technologies in terms of low losses. Other technologies, e.g. flywheels, are also suitable and when lifetime and maintenance costs are included, may be preferable. When power fluctuation occurs in the system, the battery energy storage system can be used to level the power fluctuation by charging and discharging operation. Also, during a sag or fault the system can be used to boost the stability margin by absorbing active power from the wind farm. Many STATCOMs have a (limited) transient overload capability and this can be used during sags or faults. We have been able to develop a hybrid system.

\section{Results}

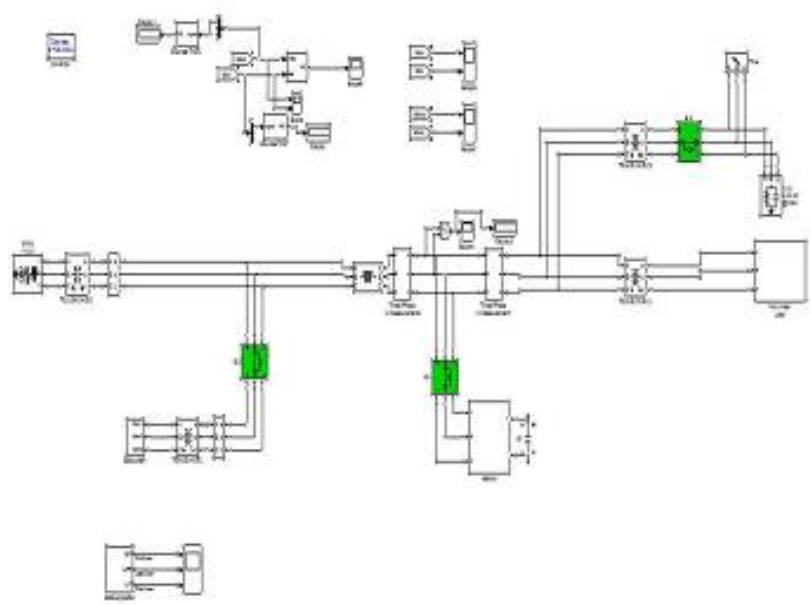

Figure 4: Proposed MATLAB simulation model

We have connected a STATCOM for removal of harmonics and the result of the simulation are given below

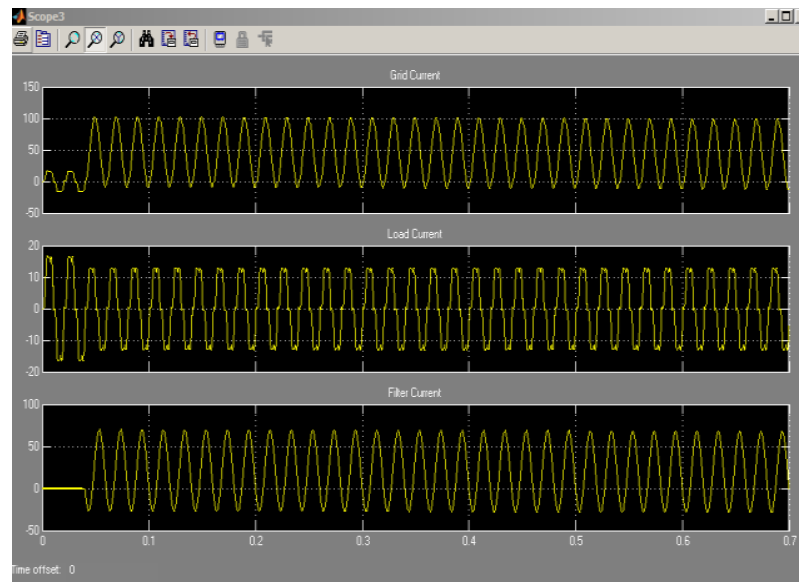

Figure 5: Waveform of Grid Current, Load Current and Filter current

\section{Volume 5 Issue 6, June 2016 www.ijsr.net}




\section{International Journal of Science and Research (IJSR) \\ ISSN (Online): 2319-7064}

Index Copernicus Value (2013): 6.14 | Impact Factor (2015): 6.391

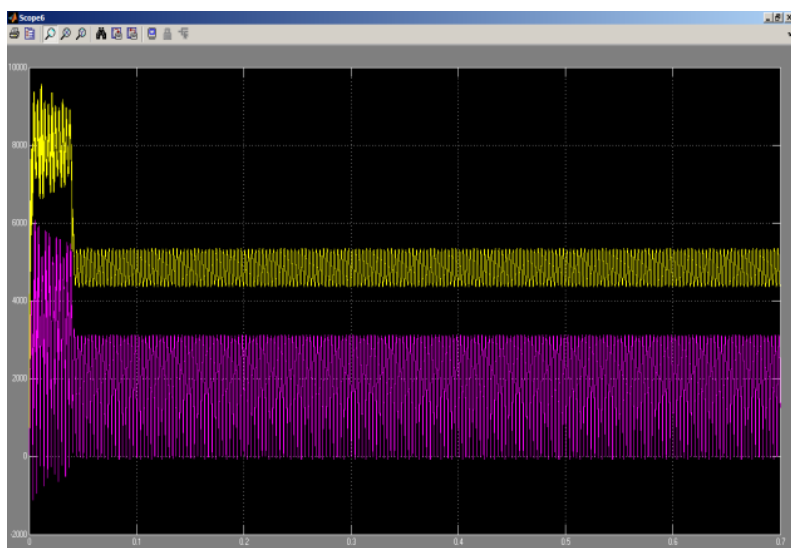

Figure 6: Active power and reactive power of system

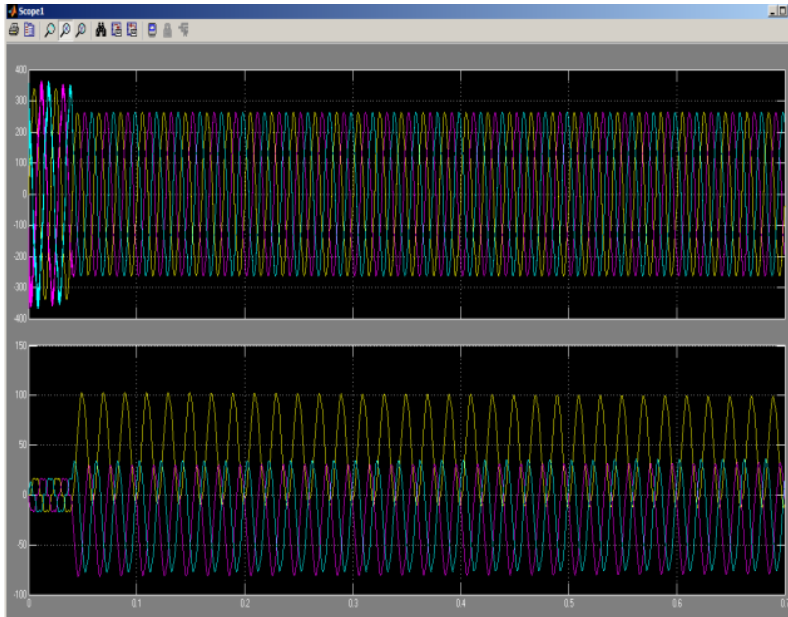

Figure 7: Waveform showing harmonic elimination

In figure 7 above we observe that when the STATCOM comes into play at time $0.05 \mathrm{sec}$, then the harmonics are reduced.

\section{Conclusion}

In this work non-linear load like simple AC to DC rectifiers have been used. In this work we have examined the STATCOM hysteresis control technique for harmonic cancellation with load tracking in a system where a wind turbine is present and we observe that the STATCOM is able to reduce harmonics.

\section{References}

[1] 'EurObserv'ER annual report - the State of Renewable Energies in Europe', Management of Environmental Quality: An International Journal, 2013..

[2] J. Seif, (2015, January 23). Projet pilote à Beyrouth. Une central solaire unique au monde. Retrieved February 26, 2015 ,

http://magazine.com.lb/index.php/fr/component/k2/item/ 10683-projetpilote-à-beyrouth-une-centrale-solaireunique-aumonde? issue id=166.

[3] Y. Ali, (2012, May 10). Hawa Akkar plans 60-MW wind farm project in Lebanon - See News Renewable. Retrieved February 26, 2015, from http://renewables.seenews.com/news/hawa-akkar-plans60-mwwind- farm-project-in-lebanon-274601
[4] Bruce G. Colpitts, "Teaching Transmission Lines: A Project of Measurement and Simulation", IEEE TRANSACTIONS ON EDUCATION, VOL. 45, NO. 3 AUGUST 2002

[5] S. W. Mohod and M. V. Aware, 'Power quality issues \&it's mitigation technique in wind energy generation', 2008 13th International Conference on Harmonics and Quality of Power, pp. 1-6, 2008.

[6] S. Mohod and M. Aware, 'A STATCOM-Control Scheme for Grid Connected Wind Energy System for Power Quality Improvement', IEEE Systems Journal, vol. 4, no. 3, pp. 346-352, 2010.

[7] M. I. M. Montero, E. R. Cadaval, and F. B. Gonzalez, 'Comparison of Control Strategies for Shunt Active Power Filters in Three-Phase Four-Wire Systems', IEEE Transactions on Power Electronics, vol. 22, no. 1, pp. 229-236, 2007.

[8] J. Delgado, "Gestão da Qualidade Total Aplicada ao Sector do Fornecimento da Energia Eléctrica", Thesis submitted to fulfilment of the requirements for the degree of $\mathrm{PhD}$. in Electrotechnical Engineering, Coimbra, September 2002.

[9] "The Two Seconds Problem", American Superconductor and EPRI Research, March 1998.

[10]EPRI Power Delivery Group, "The Future of Power Delivery in the 21st Century", 1999.

[11]M. Bollen, "Understanding Power Quality Problems Voltage Sags and Interruptions", IEEE Press Series on Power Engineering - John Wiley and Sons, Piscataway, USA (2000).

[12] M. McGranaghan, "Costs of Interruptions", in proceedings of the Power Quality 2002 Conference, Rosemont, Illinois, pp 1-8, October 2002..

[13]D. Chapman, "Costs of Poor Power Quality”, Power Quality Application Guide - Copper Development Association, March 2001.

[14]EPRI, "Creating the Electricity Infrastructure for a Digital Society", UIE-2000 Conference, Lisbon, 1- 3, November 2000.

[15] http://www.esma-cap.com

[16]P. Ribeiro, B. Johnson, M. Crow, A. Arsoy, Y. Liu, "Energy Storage Systems for Advanced Power Applications", Proceedings of the IEEE, vol 89, no. 12, December 2001.

[17] Shude Yang, Xiangqian Tong, Hao Zhang "Study on Power Dynamic Transfer Characteristics of Wind Power Generation System" IEEE 2014.

[18]A. Arulampalam, M. Barnes, N. Jenkins and J.B. Ekanayake "Power quality and stability improvement of a wind farm using STATCOM supported with hybrid battery energy storage" IEE Proc.-Gener. Transm. Distrib., Vol. 153, No. 6, November 2006.

[19] Shiny K.George,FossyMary Chacko "Comparison of Different Control Strategies of STATCOM for Power Quality Improvement of Grid Connected Wind Energy System" IEEE 2013.

[20] M. J. Ghorbanian1, F. Goodarzvand, A. Poudaryaei, W.N.L Mahadi "Power quality improvement of grid connected doubly fed induction generator using STATCOM and BESS" 2014 4th International Conference on Engineering Technology and Technopreneuship (ICE2T)

\section{Volume 5 Issue 6, June 2016} www.ijsr.net 


\section{International Journal of Science and Research (IJSR) \\ ISSN (Online): 2319-7064}

Index Copernicus Value (2013): 6.14 | Impact Factor (2015): 6.391

[21] N.Nirmala Mr.V.Suresh Kumar "A STATCOM-Control Scheme for Wind Energy System to Improve Power Quality" Information Communication and Embedded Systems (ICICES), 2013

[22] K.R.Sujal,.Jacob RagJend "Power Quality Improvement in Grid Connected Wind Energy System Using STATCOM" 2012 International Conference on Computing, Electronics and Electrical Technologies [ICCEET]

Volume 5 Issue 6, June 2016 www.ijsr.net 